\title{
The relation between anxiety and functional constipation: A multicenter study in Iranian medical interns
}

\author{
Azizollah Yousefi ${ }^{1}$, Babak Kardarian ${ }^{2}$, Seyed Mojtaba Hashemi ${ }^{3}$ and Samileh Noorbakhsh ${ }^{*}$ \\ ${ }^{1}$ Pediatric Growth and Development Research Center, Institute of Endocrinology and Metabolism, Iran University of Medical Sciences, Tehran, Iran \\ ${ }^{2}$ Iran University of Medical Sciences, Tehran, Iran \\ ${ }^{3}$ Arak University of Medical Sciences, Arak, Iran \\ ${ }^{4}$ Department of Pediatric Infectious Diseases, Iran University of Medical Sciences, Tehran, Iran
}

\begin{abstract}
Background: Functional constipation and its-related predisposing factors are so frequent among medical staff.

The aim of study: To determine the prevalence of functional constipation and its relation to psychological disorders among Iranian medical interns.

Methods: This multicenter, cross-sectional study was performed on 369 medical interns working at 5 main educational hospitals affiliated by universities of medical sciences in Iran during 2016-2017. The questionnaires related to the ROME criteria definitive for functional constipation were raised to confirm or reject definitive diagnosis of disease. To assess depression, anxiety and stress status of the participants, it was used the Persian version of the DASS-21 questionnaire that was previously validated by the Iranian researchers.
\end{abstract}

Results: Overall, the prevalence of functional constipation in medical interns was $26.3 \%$; and was more frequent in female gender ( $\mathrm{p}=0.043$ ). It was not related to depression in cases $(\mathrm{p}=0.1$ ) or baseline parameters (marital status, body mass index, severity of depression, or degree of stress status). But was related to severity of anxiety $(\mathrm{p}=0.004)$ and irregular eating breakfast $(\mathrm{p}=0.041)$; deliberately ignoring defecation $(\mathrm{p}=0.010)$.

Conclusion: It can be concluded high prevalence of functional constipation in medical interns especially in female gender, cases with low rate of eating breakfast, and deliberately ignoring defecation all might indicate the major role for anxiety in functional constipation in Iranian medical interns. Thus, the psychologic consults programs for modifying the anxiety in cases with functional constipation might be helpful.

\section{Introduction}

Chronic constipation is a common global problem affecting different components of quality of life [1]. Although many disorders can reduce patients' survival, constipation general reduces the level of patients' quality of live [2]. In prolonged situations, chronic constipation may lead to some annoying complications such as anal fissure, rectal ulcers, colon volvulus, as well as increased risk for colon polyps and even carcinoma $[3,4]$. The overall prevalence of chronic constipation ranged widely from $2 \%$ to $30 \%$ in general population [5]. Interestingly, constipation generally involves different physical, mental, social, and even economic aspects in every age subgroups and thus can confound productivity and the presence of people in the workplace, family, social environments and daily activities. The individuals affected by chronic constipation may lose their employment conditions (about 2.4 days per month) because of deterioration of disease symptoms. In a population-based survey in Canada, those who suffering functional constipation had low quality of life level as compared to control groups [2]. In another study, the productivity of people affected by functional constipation decreased by $30 \%$. Also, the efficiency was reduced by at least $21 \%$ in $60 \%$ of the cases [6]. In total, chronic constipation is mainly diagnosed based on the ROME III criteria [7]. In this regard, the definitive criteria of chronic constipation include the existence of two or more of the following symptoms for the last three months with symptom onset at least six months prior to diagnosis: a. Straining during at least $25 \%$ of defecations b. Lumpy or hard stools in at least $25 \%$ of defecations c. Sensation of incomplete evacuation for at least $25 \%$ of defecations d. Sensation of anorectal obstruction/blockage for at least $25 \%$ of defecations e. Manual maneuvers to facilitate at least $25 \%$ of defecations (e.g., digital evacuation, support of the pelvic floor) f. Fewer than three defecations per week [7]. The main etiologies for constipation can stratified as the primary and secondary. In primary or functional constipation, there is no physiological disturbance such as pelvic disorders or bowel obstruction, but some habits such as lifestyle, low intake of dietary fiber, lack of physical activity, or psychological problems may predispose the subjects to constipation [8-10]. In this regard, the critical role of some conditions including deliberative suppression of defecation, undesirable work shifts, or stressful occupational status may increase the likelihood and severity of functional constipation [11-14]. Because most of these predisposing factors are frequently observed among medical staff especially medical interns and students, we aimed to determine the prevalence of

${ }^{\star}$ Correspondence to: Samileh Noorbakhsh, Department of Pediatric Infectious Diseases, 4th floor, Hazrat Rasul Hospital, Niayesh Street, Satarkhan Avenue, Tehran, 14455 Islamic Republic of Iran, Tel: +98-21-66525328; Fax: +98-2166525328; E-mail: samileh_noorbakhsh@yahoo.com

Key words: anexity, functional constipation, medical staff

Received: March 19, 2020; Accepted: April 03, 2020; Published: April 08, 2020 
functional constipation and also to assess main determinants of this phenomenon among Iranian medical interns.

\section{Materials and methods}

This cross-sectional survey was performed on medical interns working at educational hospitals of five great universities of medical sciences in Iran in 2016. At baseline, the study questionnaire was distributed among medical interns with the initial consent of the participating in the study. The pointed questionnaire consisted of two general and specific parts. In general section, the baseline characteristics including gender, age, anthropometric indices, and marital status were collected and second section was specified to assessing the underlying disorders, habits or medications that might predispose them to occurring constipation. Because or targeted population included those interns suffering functional constipation, those with underlying factors should be excluded from the study. In next step, the questionnaires related to the ROME criteria definitive for functional constipation were raised to confirm or reject definitive diagnosis of disease. The validation of the Rome III diagnostic questionnaire for the adult functional constipation was done by Toghiani et al. yielding high reliability with the odd questions' values of Cronbach's alpha of 0.77 [15]. To assess depression, anxiety and stress status of the participants, it was used the Persian version of the DASS-21 questionnaire that was previously validated by the Iranian researchers [16,17]. In addition, some underlying factors and habits that might be correlated with appearance of functional constipation such as deliberately ignoring defecation, lack of regular eating breakfast, and gender were assessed as the probable determinants for constipation. Initially, participants were given an explanation of the purposes and the stages of the study and then they were asked to fulfill the questionnaire in ultimate relaxing and without the help of others. Finally, the relationship between each of the study parameters and presence of functional constipation was assessed using the statistical tools. In this regard, results were presented as mean \pm standard deviation (SD) for quantitative variables and were summarized by absolute frequencies and percentages for categorical variables. Normality of data was analyzed using the Kolmogorov-Smirnoff test. Categorical variables were compared using chi-square test or Fisher's exact test when more than $20 \%$ of cells with expected count of less than 5 were observed. Quantitative variables were also compared with t test or Mann U test. For the statistical analysis, the statistical software SPSS version 16.0 for windows (SPSS Inc., Chicago, IL) was used. P values of 0.05 or less were considered statistically significant.

\section{Results}

Of 385 individuals initially entered into the study, 16 were excluded because of underlying disorders or using some drugs influencing final study endpoints and thus 369 cases were finally analyzed. The mean total body mass index was $22.83 \pm 3.64 \mathrm{~kg} / \mathrm{m}^{2}$ ranged 15.10 to 36.93 . Totally, $60.2 \%$ were male and $39.8 \%$ were female. Regarding medical universities, $43.4 \%$ educated in Tehran University, $18.4 \%$ in Tabriz University, $24.9 \%$ in Iran University, $7.3 \%$ in Gorgan University and 6.0\% in Kermanshah University. Overall, the prevalence of functional constipation in medical interns was $26.3 \%$. As shown in Table 1, the presence of functional constipation did not depend on baseline parameters (including marital status, body mass index, severity of depression, or degree of stress status). However, as shown in Tables 1: Functional constipation was more prevalent in female than in male interns $(p=0.043)$. Those who suffered constipation had lower rate of regular eating breakfast as compared to other interns $(\mathrm{p}=0.041)$. Also, deliberately ignoring defecation was found significantly more in those who complained from functional constipation $(\mathrm{p}=0.010)$.

Moreover, the severity of anxiety was considerably higher in those suffering constipation $(\mathrm{p}=0.004)$. But depression has not related to functional constipation ( $\mathrm{p}=0.1$ ) (Table 2).

\section{Discussion}

Our study revealed functional constipation in $26.3 \%$ of Iranian medical interns, while this rate in a systematic review conducted on similar population in the United States was found to be $15.0 \%$ [18]. In another study on Iranian population regardless of educational level or occupation, the prevalence of functional constipation was estimated $2.4 \%$ to $11.2 \%$. The rate of functional constipation on Chinese and Spanish similar samples was $6 \%$ and $28.8 \%$ [19] indicating a wide prevalence range in the world. This discrepancy might be due to the difference in definitive criteria of functional constipation or the difference in cultural or social conditions. Partial lower rate of functional constipation in Iranian population may be due to the use of Iranian toilet leading better rectal defecation [20]. Also, higher

Table 1. Study characteristics in medical interns with and without constipation

\begin{tabular}{|c|c|c|c|}
\hline Factor & Constipation (+) & Constipation (-) & P value \\
\hline Female gender & $47(48.5)$ & $100936.8)$ & 0.043 \\
\hline Married status & $8(8.2)$ & $14(5.1)$ & 0.268 \\
\hline Body mass index & & & 0.395 \\
\hline Normal & $73(75.3)$ & $207(76.4)$ & \\
\hline Overweight & $22(22.7)$ & $51(18.8)$ & \\
\hline Obese & $2(2.1)$ & $13(4.8)$ & \\
\hline Rate of eating breakfast/week & & & 0.041 \\
\hline None & $27(27.8)$ & $54(19.8)$ & \\
\hline 1 to 2 days & $22(22.7)$ & $55(20.2)$ & \\
\hline 3 to 4 days & $27(27.8)$ & $62(22.8)$ & \\
\hline 5 to 6 days & $19(19.6)$ & $76(27.9)$ & \\
\hline Every day & $2(2.1)$ & $25(9.2)$ & \\
\hline No/seldom & & & 0.004 \\
\hline Sometimes & $46(47.4)$ & $166(61.0)$ & \\
\hline Frequently & $11911.3)$ & $11(4.0)$ & \\
\hline Always & $0(0.0)$ & $4(1.5)$ & \\
\hline & & & \\
\hline Deliberately ignoring defecation & & & \\
\hline & & & \\
\hline
\end{tabular}

Table 2. Psychological disorders in medical interns with and without constipation

\begin{tabular}{|c|c|c|c|}
\hline Factor & Constipation (+) & Constipation (-) & P value \\
\hline Depression & & & 0.100 \\
\hline None & $43(44.3)$ & $152(55.9)$ & \\
\hline Mild & $22(22.7)$ & $38(14.0)$ & \\
\hline Moderate & $22(22.7)$ & $52(19.1)$ & \\
\hline Severe & $8(8.2)$ & $16(5.9)$ & \\
\hline Very severe & $2(2.1)$ & $14(5.1)$ & \\
\hline Anxiety & & & \\
\hline None & $36(37.1)$ & $151(55.5)$ & \\
\hline Mild & $11911.3)$ & $33(12.1)$ & \\
\hline Moderate & $31(32.0)$ & $56(20.6)$ & \\
\hline Severe & $17(17.5)$ & $22(8.1)$ & \\
\hline Very severe & $2(2.1)$ & $10(3.7)$ & \\
\hline Stress grade & & & \\
\hline None & $46(47.4)$ & $148(54.4)$ & \\
\hline Mild & $25(25.8)$ & $60(22.1)$ & \\
\hline Moderate & $21(21.6)$ & $41(15.1)$ & \\
\hline Severe & $5(5.2)$ & $18(6.6)$ & \\
\hline Very severe & $0(0.0)$ & $5(1.8)$ & \\
\hline & & & \\
\hline
\end{tabular}


consumption of dietary fibers and rice as an Iranian special regimen is another reason these claim [21]. Additionally, higher prevalence of functional constipation among medical interns as compared to general population may be due to failure to pass the stool at workplace for a long time, lack of regular sleeping, inadequate dietary regimen in hospitals, and low consumption of fruits, vegetables, and liquids due to high workload. As shown well in our survey, a significant association was revealed between the presence of constipation and deliberately ignoring defecation as a common behavior among interns. Such causality has been previously shown among nurses [22]. To prove this finding, a similar study on Brazilian medical students, the prevalence of functional constipation was about 35\% [23]. In another study by Lin et al. in Malaysian, functional constipation was found in $16.2 \%$ of medical students [24].

As similarly shown in our study, most of previous studies could found higher rate of functional constipation in female than in male medical students that can be related to inhibitory effects of estrogenic hormones on B smooth muscle cells $[25,26]$.

In our study, anxious individuals suffered more from constipation that was consistent with previous reports. This causality can be related to autonomic nervous system defects more seen in healthcare workers, however this association was not observed between constipation and other psychological abnormalities such as depression and stress. However similar to our study, Hosseinzadeh et al. showed higher prevalence of mood disorders among patients with constipation as compared to general population and thus recommended a principle planning for psychological treatment interventions among those who suffering constipation to minimize this gastrointestinal complication.

Also, in 1970, the role of dietary fibers on gastrointestinal motility was introduced $[27,28]$. After that time, the association between the use of fibers and improvement in constipation was frequently reported [28-32].

Limitation of study: Because of our study subjects were not smokers, the effect of cigarette smoking on functional constipation remained uncertain. But, it has been suggested that the use of nicotine can trigger constipation because of its Para-sympathomimetic effects of nicotine [33], however in some reports, no difference was found in the prevalence of constipation between smokers and non-smokers [34]. The beneficial effects of exercise on improvement or progression of constipation has been also questioned $[35,36]$, however it seems that regular exercise activities may increase intestinal movements secondary to reduced mucosal blood flow as well as hormonal or neurogenic effects of exercise [37].

\section{Conclusion}

In total, it can be concluded high prevalence of functional constipation in medical interns especially in female gender, cases with low rate of eating breakfast, and deliberately ignoring defecation all might indicate the major role for anxiety in functional constipation in Iranian medical interns. Thus, the psychologic consults programs for modifying the anxiety in cases with functional constipation might be helpful.

\section{References}

1. Dennison C, Prasad M, Lloyd A, Bhattacharyya SK, Dhawan R, et al. (2005) The health-related quality of life and economic burden of constipation. Pharmacoeconomics 23: 461-476.

2. Sanchez MI, Bercik P (2011) Epidemiology and burden of chronic constipation. Can J Gastroenterol 25: 11B-15B. [Crossref]
3. Singh G, Kahler K, Bharathi V (2005) Constipation in adults: Complications and comorbidities. Gastroenterology 128: A154.

4. Mitra D, Davis KL, Baran RW (2007) Healthcare costs and clinical sequelae associated with constipation in a managed care population. Am J Gastroenterol 102: 2.

5. Andromanakos N, Skandalakis P, Troupis T, Filippou D (2006) Constipation of anorectal outlet obstruction: Pathophysiology, evaluation and management. Journal of Gastroenterology and Hepatology 21: 638-646.

6. Eoff JC et al. (2008) Optimal treatment of chronic constipation in managed care: review and roundtable discussion. J Manag Care Pharm 14: 1-15.

7. Warwick S, Crispin C (2010) Managing constipation in adults. Australian Prescriber 33: 116-119.

8. Chatoor D, Emmnauel A (2009) Constipation and evacuation disorders. Best Pract Res Clin Gastroenterol 23: 517-530.

9. Murakami K, Okubo H, Sasaki S (2006) Dietary intake in relation to self-reported constipation among Japanese women aged 18-20 years. Eur J Clin Nutr 60: 650-657.

10. Johanson JF, Kralstein J (2007) Chronic constipation: a survey of the patient perspective. Aliment Pharmacol Ther 25: 599-608.

11. Walia R, Mahajan L, Steffen R (2009) Recent advances in chronic constipation. Curr Opin Pediatr 21: 661-666.

12. Kunimoto M, Nishi M, Sasaki K (1998) The relation between irregular bowel movement and the lifestyle of working women. Hepatogastroenterology 45: 956-960.

13. Murakami, Sasaki S, Okubo H, Takahashi Y, Hosoi Y, et al. (2007) Freshmen in Dietetic Courses Study II Group. Association between dietary fiber, water and magnesium intake and functional constipation among young Japanese women. Eur J Clin Nutr 61: 616-622.

14. Nojkov B, Rubenstein JH, Chey WD, Hoogerwerf WA (2010) The impact of rotating shift work on the prevalence of irritable bowel syndrome in nurses. Am J Gastroenterol 105: 842-847.

15. Toghiani A, Maleki I, Afshar H, Kazemian A (2016) Translation and validation of the Farsi version of Rome III diagnosticquestionnaire for the adult functional gastrointestinal disorders. J Res Med Sci 21: 103.

16. Moradipanah F (2005) Effects of Music therapy on anxiety, stress and depression of patients undergoing cardiac catheterization. Tarbiat Modares University, Faculty of medical sciences, pp: 42-48.

17. Jamshidi N, Abbaszadeh A, Kalyani MN (2009) Effects of video information on anxiety, stress and depression of patients undergoing coronary angiography. Pakistan Journal of Medical Sciences 25: 901-905.

18. Higgins PD, Johanson JF (2004) Epidemiology of constipation in North America: A systematic review. Am J Gastroenterol 99: 750-759.

19. Iraji N, Keshteli AH, Sadeghpour S, Daneshpajouhnejad P, Fazel M, Adibi P (2012) Constipation in Iran: SEPAHAN Systematic Review No. 5. Int J Prev Med 3: 34-41.

20. O'Brien MD, Camilleri M, von der Ohe MR, Phillips SF, Pemberton JH, et al. (1996) Motility and tone of theleft colon in constipation: a role in clinical practice? $\mathrm{Am} \mathrm{J}$ Gastroenterol 91: 2532-2538.

21. Davudi KH, Volkova LI (2007) Structure of nutrition in Iranian population. Vopr Pitan 76: $56-61$.

22. Lim YJ, Rosita J, Chieng JY, Hazizi AS (2016) The prevalence and symptoms characteristic of functional constipation using rome III diagnostic criteria among tertiary education students. PLoS One 11: e0167243.

23. Xiao ZL, Pricolo V, Brancani P, Behar J (2005) Role of progesterone signaling in the regulation of G-protein levels in female chronic constipation. Gastroenterology 128: $667-675$.

24. Cheng L, Pricolo VE, Biancani P, Behar J (2008) Over expression of progesterone receptor B increases the sensitivity of human colon muscle cells to progesterone. Am J Physiol Gastrointest Liver Physiol 295: G493-G502.

25. Burkitt DP, Walker AR, Painter NS (1974) Dietary fiber and disease. JAMA 229: 10681074.

26. Burkitt DP, Walker AR, Painter NS (1972) Effect of dietary fibre on stools and the transit-times, and its role in the causation of disease. Lancet 2: 1408-1412.

27. Graham DY, Moser SE, Estes MK (1982) The effect of bran on bowel function in constipation. Am J Gastroenterol 77: 599-603. 
28. Anti M, Pignataro G, Armuzzi A, Valenti A, Iascone E, et al. (1998) Water supplementation enhances the effect of high fiber diet on stool frequency and laxative consumption in adult patients with functional constipation. Hepatogastroenterology 45: $727-732$.

29. Chan AO, Leung G, Tong T, Wong NY (2007) Increasing dietary fiber intake in terms of kiwifruit improves constipation in Chinese patients. World J Gastroenterol 13: 47714775 .

30. Suares NC, Ford AC (2011) Systematic review: the effects of fibre in the management of chronic idiopathic constipation. Aliment Pharmacol Ther 33: 895-901.

31. Hajek P, Gillison F, McRobbie H (2003) Stopping smoking can cause constipation. Addiction 98: 1563-1567.

32. Choung RS, Locke GR, Schleck CD, Zinsmeister AR, Talley NJ (2007) Cumulative incidence of chronic constipation: apopulation- based Study 1988-2003. Aliment Pharmacol 26: 1521-1528.
33. Dukas L, Willett WC, Giovannucci EL (2003) Association betweenphysical activity, fiber intake, and other lifestyle variablesand constipation in a study of women. $A m J$ Gastroenterol 98: 1790-1796.

34. De Schryver AM, Keulemans YC, Peters HP, Akkermans LM, Smout AJ, et al. (2005) Effects of regular physical activity on defecation. pattern in middle-aged patients complaining of chronic constipation. Scand J Gastroenterol 40: 422-429.

35. Oettlé GJ (1991) Effect of moderate exercise on bowel habit. Gut 32: 941-944.

36. Emmanuel AV, Mason HJ, Kamm MA (2001) Relationship between psychological state and level of activity of extrinsic gutinnervation in patients with a functional gut disorder. Gut 49: 209-213.

37. Nehra V, Bruce BK, Rath-Harvey DM, Pemberton JH, Camilleri M (2000) Psychological disorders in patients with evacuation disorders and constipation in a tertiary practice. Am J Gastroenterol 95 : 1755-1758.

Copyright: $\odot 2020$ Yousefi A. This is an open-access article distributed under the terms of the Creative Commons Attribution License, which permits unrestricted use, distribution, and reproduction in any medium, provided the original author and source are credited. 